In passing judgment upon any particular case these broad relations should be kept in mind, and in what I have to say I do not wish to be understood as expressing any opinion concerning the conditions which have existed at the Agricultural College in the past, or at the Normal School at the present time. There are, however, two points in Professor Cockerell's communication to which I desire to call especial attention. Not that the professor has intentionally misrepresented the matter, but because of the inference which might easily be drawn. The conditions in two of the several public institutions of the territory are made the basis of several broad and general inferences. I am assured by President Light of the Normal School of Silver City that the relations of the board of regents of that institution and the faculty have been uniformly harmonious, and that the institution is wholly free from political influences in its administration. Professor Cockerell states in his article that the Normal School at Las Vegas 'has had until now a most fortunate immunity from political interference.' And I wish to state that it has never been my pleasure to know of a public institution so free from political influences as the University of New Mexico, over which I have the honor to preside.

Again, Professor Cockerell says: 'It can not be overlooked that the governors of New Mexico, who appoint the regents of the higher institutions, are responsible for the general unsatisfactory character of these bodies.' I wish to object to the professor's use of the term 'general' and 'these bodies,' and to state that, at least in the case of the University of New Mexico, a more estimable body of men could not be selected from any community either in this territory or any of the eastern states of the Union.

Hon. Ex-Governor E. S. Stover has always been a staunch friend of education. Hon. F. W. Clancy is one of the old and leading attorneys of the city of Albuquerque. Dr. James H. Wroth is one of the leading physicians of the city and surgeon for the Santa Fe Railroad. Hon. Henry L. Waldo, of Las
Vegas, is general solicitor for the Santa Fe Railroad and ex-chief justice; and Hon. E. $\mathrm{V}$. Chavez is another of the leading attorneys of Albuquerque. There are three Democrats and two Republicans. These men are all appointees of governors of New Mexico, and three of them originally by Governor Otero, and all have been reappointed by him at the expiration of their terms.

As to the other institutions of the territory, I can only say that their boards, as far as I know, are made up of men who are leading and influential citizens.

In closing, permit me to say that, in my judgment, the higher institutions of learning of the territory of New Mexico are in general fully as free from political influences as are those of any other state of our Union, and it is hardly right to take the exceptional unfortunate cases of disorder as indicative of the general condition.

$$
\begin{aligned}
& \text { University of New Mexico, } \\
& \text { Albuquerque, N. M. }
\end{aligned}
$$

\section{THE PROPOSED BIOLOGICAL STATIONS AT THE TORTUGAS.}

To the Editor of Science: Referring to the correspondence from zoologists as to the need for one or more stations for biological research work in southern waters, I notice the preponderance in favor of Tortugas. Aside from its suitability for deep-sea fauna there seem to be other items to commend it, such as: The flag which floats over it, available buildings, subsistence, accessibility and, not the least in importance, communication. It may not be known to the committee or to your readers that the United States government departments are planning a chain of wireless telegraphic communication along the coast and to the Antilles. Among those now installed are stations of the De Forest Company at Hatteras and Porto Rico; others are proposed at Miami, Key West, Havana, ets. These will be in demand for commercial marine as well as naval and military purposes.

A glance at the map will show that Tortugas can easily be hitched on to this system viâ Key West (and equally a station at Cul- 
ebra vîa San Juan) with very little added cost or trouble. No cable will be required, but only a mast and some sort of light motor. The operator could be improvised easily by one of the resident staff familiar with the Morse code. The greater comfort and convenience of life with this facility at hand would be cheaply purchased.

I am assured by the executive of the American De Forest Company-whose office is at 100 Broadway-that they would welcome the establishment of a science station near their field and cooperate in any reasonable way for the handling of any commercial business that might come that way.

Believing that this suggestion may have further weight in the deliberations, I forward this with the concurrence of Dr. De Forest's organization.

R. T. Colburn.

Room C, 120 Broadway, New York.

\section{SHORTER ARTICLES.}

SOME OF THE DANGERS OF FORMAL.

So much use is being made of formal* in the conservation of anatomical and zoological specimens, as well as for purposes of disinfection, and it has become so readily accessible to persons unfamiliar with some of its dangerous properties, that it may not be amiss to point out some of these. Of course every one who works with formal has experienced the disagreeable coryza and coughing arising from the inhalation of the fumes of this drug, as well as the irritating effect upon the ocular conjunctivæ. Although no fatal case of poisoning by inhalation has been recorded, one may take warning from the experimental results of M. H. Fisher, $\nmid$ who found that the exposure of various animals (guinea-pigs, rats, cat and $\mathrm{dog}$ ) to the fumes of formaldehyd for one or one and a half hours produced in them a fatal pneumonia, tracheitis and bronchitis, after only three grams of paraformaldehyd had been

* On the use of formal as a term more suitable than formalin, formol or formalose, cf. B. B. Stroud's papers in The American Naturalist, January 1 and May 1, 1897.

$\dagger$ M. H. Fischer, 'The Toxic Effects of Formaldehyd and Formalin,' Jour. of the Boston Soc. of Med. Sci., Vol. 1, October 16, 1900. volatilized in the room. Only recently, in this city (New York) a woman was overcome by formal fumes. Her younger child had had diphtheria; the disinfecting was done in the afternoon and the family moved in again about seven o'clock. The odor was still strong, but the woman thought it would pass away and went to bed. Later she awoke with her head ringing, and was just able to crawl to the hall and summon help. The children were not ill at all. The writer has noticed in himself, after working in an atmosphere fairly charged with formal fumes, a state of depression and dulness which does not wear off until after spending some time in fresh air. A long exposure might bring about a serious condition, though Kenyon* expresses it as his belief that the vapor does not endanger inhabitants of rooms, and cites an experiment on a calf kept in an atmosphere of two per cent. formaldehyd for five hours, which only produced a slight cough and some watering of the eyes, both symptoms disappearing on the animal's going into fresh air.

The effect of formal on the skin is well known. $\dagger$ The cuticle is killed; it hardens, cracks and desquamates; in some individuals this is attended by an eczematous rash. The nerve terminals in the skin are paralyzed, producing an annoying numbness. Where the skin is cracked, the entrance of formal becomes very painful.

The palpable influence of formal on the glandular action of the skin led Dr. E. C. Spitzka to recommend it in two instances where patients consulting him mentioned their being affected with the annoying condition of perspiring hands and feet. They began with a dilute solution, used as a wash several times a day, and gradually increasing its strength, not exceeding one of ten per cent. of the commercial preparation. In both cases the effect was gratifying after two or three weeks, and in one of them the permanency of the cure seems guaranteed by the non-return of the trouble for three years thereafter.

To laboratory workers one of the great dangers is the accidental splashing of drops

* F. C. Kenyon, Scrence, VI., 1897, p. 737.

$\dagger$ W. H. Dall, Science, VI., 1897, p. 633. 